\title{
Resveratrol Triggers Apoptosis Through Regulating Ceramide Metabolizing Genes in Human K562 Chronic Myeloid Leukemia Cells
}

\author{
Melis Kartal \\ Izmir Institute of Technology, Faculty of Science, Department of Molecular Biology and Genetics, \\ Gulbahce Campus, Izmir, Turkey
}

Guray Saydam and Fahri Sahin

Ege University, Faculty of Medicine, Department of Hematology, Bornova, Izmir, Turkey

\section{Yusuf Baran}

Izmir Institute of Technology, Faculty of Science, Department of Molecular Biology and Genetics, Gulbahce Campus, Izmir, Turkey

\begin{abstract}
Resveratrol, an important phytoalexin in many plants, has been reported to have cytotoxic effects on various types of cancer. Ceramide is a bioactive sphingolipid that regulates many signaling pathways, including cell growth and proliferation, senescence and quiescence, apoptosis, and cell cycle. Ceramides are generated by longevity assurance genes (LASS). Glucosylceramide synthase (GCS) and sphingosine kinase-1 (SK-1) enzymes can convert ceramides to antiapoptotic molecules, glucosylceramide, and sphingosine-1-phosphate, respectively. C8:ceramide, an important cell-permeable analogue of natural ceramides, increases intracellular ceramide levels significantly, while 1-phenyl-2-decanoylamino3-morpholino-1-propanol (PDMP) and SK-1 inhibitor increase accumulation of ceramides by inhibiting GCS and SK-1, respectively. Chronic myelogenous leukemia (CML) is a hematological disorder resulting from generation of $\mathrm{BCR} / \mathrm{ABL}$ oncogene. In this study, we examined the roles of ceramide metabolizing genes in resveratrolinduced apoptosis in K562 CML cells. There were synergistic cytotoxic and apoptotic effects of resveratrol with coadministration of C8:ceramide, PDMP, and SK-1 inhibitor. Interestingly, there were also significant increases in expression levels of LASS genes and decreases in expression levels of GCS and SK-1 in K562 cells in response to resveratrol. Our data, in total, showed for the first time that resveratrol might kill CML cells through increasing intracellular generation and accumulation of apoptotic ceramides.
\end{abstract}

Submitted 8 February 2010; accepted in final form 26 June 2010.

Address correspondence to Yusuf Baran, Izmir Institute of Technology, Department of Molecular Biology and Genetics, 35430, Urla, Izmir, Turkey. Phone: + 90232 7507515. Fax: + 902327507509. E-mail: yusufbaran@iyte.edu.tr

\section{INTRODUCTION}

Resveratrol (3,5,4'-trans-trihydroxystilbene) is a natural product generated in various plants, especially in the skin and seeds of red grapes, to protect them in stress conditions, such as fungal infections or UV irradiation $(1,2)$. Resveratrol has drawn increasingly more attention recently since it has antiinflammatory, antimetastatic, cardioprotective, chemopreventive, cancer-preventive, apoptosis inducer, and radio-sensitizer potentials (3-5). Resveratrol affects the processes of tumor initiation, promotion, and progression (6). It is very well known that resveratrol can bind directly to DNA and RNA. Therefore, it can protect DNA from genotoxic effects of mutagens. On the other hand, resveratrol can also inhibit DNA topoisomerase II enzyme and induce apoptosis (6). Different mechanisms were explained for resveratrol-induced apoptosis, such as repression of NF- $\kappa$ B and STAT3 pathways and downregulation of cyclin D1, Bcl-2, Bcl-XL, XIAP, and AKT genes (7). We have previously showed the antiproliferative effect of resveratrol on cultured chronic myeloid leukemia (CML) cells (1). CML is a clonal hematological disorder, which raises from reciprocal translocation between the BCR (break point cluster) gene on chromosome 22 and the ABL (Abelson leukemia virus oncogene) gene on chromosome $9, \mathrm{t}(9,22)(\mathrm{q} 34, \mathrm{q} 11)$, resulting in the formation of BCR/ABL fusion protein (8). This fusion protein possesses constitutive tyrosine kinase activity (9). Furthermore, BCR/ABL induces several signal transduction pathways that mediate cellular proliferation and cause the disruption of the genetic maintenance. Although there are very effective treatment agents targeting $\mathrm{BCR} / \mathrm{ABL}$ oncogene, emergence of the resistance is a significant problem for the treatment of CML. However, the roles of bioactive 
sphingolipids in resveratrol-induced apoptosis in cultured CML cells have not been examined previously.

Ceramide, the most important bioactive sphingolipid, constitutes a signaling mediator of various biological activities, including cell cycle arrest, cell senescence, cell migration and adhesion, differentiation, and apoptosis in various types of normal and tumor cells (10). It has been shown that intracellular concentrations of ceramides are increased in response to chemotherapy, ionizing radiation and several environmental stress conditions (11). Ceramide levels are regulated by longevity assurance genes (LASS) that synthesize ceramides and by glucosyleceramide synthase (GCS) and sphingosine kinase-1 (SK-1) that convert apoptotic ceramides to antiapoptotic glucosylceramide and sphingosine-1-phosphate (S1P), respectively (12). Unlike ceramides, increasing concentrations of glucosylceramide and S1P in the cell promote cell growth and proliferation (12). In addition, it has been reported that elevated levels of GCS and S1P cause multidrug resistance in many cancer cells (12-14). We have previously shown that ceramides have significant roles in the sensitivity and resistance of CML cells to imatinib (10). In addition, there are some other studies showing the effects of resveratrol on ceramide generation. Ersilia Dolfini et al. have shown that resveratrol may prevent the growth of MDA-MB-231 breast cancer cells through inducing de novo ceramide generation (15). In another study, it was also shown that resveratrol triggers autophagy in gastric cancer cells via increasing intracellular ceramide levels (16).

We and some others have reported that targeting ceramide metabolism induces apoptotic signaling pathways and, therefore, promotes apoptosis in various types of cancer, including CML $(10,17)$. In this study, our hypothesis was that ceramide generating and ceramide clearance genes may be involved in resveratrol-induced apoptosis. We also hypothesized that targeting bioactive sphingolipid metabolism by mimetics/ inhibitors that trigger ceramide generation and accumulation can increase apoptotic effects of resveratrol on K562 CML cells.

\section{MATERIALS AND METHODS}

\section{Cell Line and Chemicals}

Human K562 CML cells were obtained from German Collection of Microorganisms and Cell Cultures (Germany). Resveratrol (trans-3,4', 5-trihydroxystilbene) was obtained from Sigma Aldrich (St. Louis, MO). The stock solution of resveratrol was dissolved in dimethylsulfoxide (DMSO) at a concentration of $10 \mathrm{mmol} / \mathrm{mL}$, stored at $-20^{\circ} \mathrm{C}$, and diluted in cell culture medium. C8:ceramide, 1-phenyl-2-decanoylamino-3morpholino-1-propanol (PDMP), and SK-1 inhibitor were obtained from Cayman Chemicals (Ann Arbor, MI) and dissolved in DMSO. Penicillin-streptomycin, RPMI1640, and fetal bovine serum were obtained from Invitrogen (Paisley, UK).

\section{Culture Conditions}

The $\mathrm{Ph}(+)$ human K562 CML cells were cultured in RPMI1640 growth medium containing $10 \%$ fetal bovine serum and $1 \%$ penicillin-streptomycin at $37^{\circ} \mathrm{C}$ in $5 \% \mathrm{CO}_{2}$.

\section{Measurement of Cell Growth by XTT Assay}

The IC50 values (drug concentration that inhibits cell growth by 50\%) of resveratrol and C8:ceramide, and the IC10 values (drug concentration that inhibits cell growth by 10\%) of PDMP and SK-1 inhibitor were determined by XTT cell proliferation assay. In short, $2 \times 10^{4}$ cells/well were seeded into 96-well plates containing $100 \mu \mathrm{l}$ of the growth medium in the absence or presence of increasing concentrations of resveratrol, C8:ceramide, PDMP, or SK-1 inhibitor and then incubated at $37^{\circ} \mathrm{C}$ in $5 \% \mathrm{CO}_{2}$. After $72 \mathrm{~h}$ incubation period, cells were treated with $50 \mu \mathrm{l}$ XTT for $4 \mathrm{~h}$. Then, the plates were read under 492-nm wavelengths by ELISA reader (Thermo Electron Corporation Multiskan Spectrum, Vantaa, Finland). Finally, IC50 values of resveratrol and C8:ceramide, and IC10 values of PDMP and SK-1 inhibitor were calculated from the cell proliferation plots. We prefer to combine increasing concentrations of resveratrol with IC10 values of PDMP and SK-1 inhibitor since we have shown previously that IC10 values of these chemicals are enough to inhibit the enzyme activity and provide accumulation of ceramides in the cells (10). On the other hand, since C8:ceramide by itself triggers induction of generation of apoptotic ceramide, it can be accepted like a pro-drug. Therefore, we combined the IC50 value of C8:ceramide with increasing concentrations of resveratrol. Our main purpose in these combinations was to see if we could enhance the sensitivity of K562 cells to resveratrol by increasing intracellular concentrations of ceramides.

In order to determine the possible synergistic effects of resveratrol in combination with C8:ceramide, PDMP, or SK1 inhibitor, $2 \times 10^{4} \mathrm{~K} 562$ cells were seeded into each well of a 96-well plate containing $100 \mu 1$ of the growth medium. Then IC50 value of C8:ceramide or IC10 value of PDMP or SK-1 inhibitor were applied onto the cells, and the plates were incubated at $37^{\circ} \mathrm{C}$ in $5 \% \mathrm{CO}_{2}$ for $18 \mathrm{~h}$. This time period provides increased generation of ceramides through its induction by $\mathrm{C} 8$ :ceramide or increased accumulation of ceramides through inhibition of conversion of ceramides to glucosylceramide or sphingosine-1phosphate by PDMP or SK-1 inhibitor, respectively. Increasing concentrations of resveratrol were then applied into these plates, and they were incubated at $37^{\circ} \mathrm{C}$ in $5 \% \mathrm{CO}_{2}$. After $72 \mathrm{~h}$ incubation, cells were treated with $50 \mu \mathrm{l}$ of XTT mixture for $4 \mathrm{~h}$ and the plates were read under $492 \mathrm{~nm}$ wavelengths by ELISA reader (Thermo Electron Corporation Multiskan Spectrum, Vantaa, Finland).

\section{Evaluation of Apoptosis}

Changes in caspase- 3 enzyme activity of the cells, an important sign of apoptosis, were examined by caspase- 3 colorimetric 
assay kit (BioVision Research Products, Mountain View, CA). This assay is based on spectrophotometric detection of the chromophore $p$-nitroanilide $(p \mathrm{NA})$ after cleavage from the labeled substrate DEVD- $p$ NA that can be recognized by caspases. In short, the cells $\left(1 \times 10^{6}\right.$ cells $/ 2 \mathrm{~mL} /$ well $)$, induced to undergo apoptosis, were collected by centrifugation at $1,000 \mathrm{rpm}$ for 10 $\min$. The cells were lysed by adding $50 \mu \mathrm{l}$ of chilled cell lysis buffer and incubated on ice for $10 \mathrm{~min}$ before centrifugation at $10,000 \mathrm{~g}$ for $1 \mathrm{~min}$. Supernatants were transferred to new Eppendorf tubes, and the reaction mixture was prepared in 96-well plates by adding $50 \mu \mathrm{l}$ of $2 \times$ reaction buffer (containing $10 \mathrm{mM}$ DTT), $50 \mu 1$ of sample, and $5 \mu 1$ of DEVD-pNA substrate and incubated for $2 \mathrm{~h}$ at $37^{\circ} \mathrm{C}$ in a $\mathrm{CO}_{2}$ incubator. At the end of this period, the plate was read under $405 \mathrm{~nm}$ wavelengths by ELISA reader (Thermo Electron Corporation Multiskan Spectrum, Vantaa, Finland). The absorbance values are normalized to protein concentrations determined by Bradford assay as described previously (10).

We have also examined the loss of mitochondrial membrane potential (MMP), another important sign of apoptosis, in response to resveratrol, C8:ceramide, PDMP, and SK-1 inhibitor or combinations of resveratrol with the others in K562 cells by the APO LOGIX JC-1 Mitochondrial Membrane Potential Detection Kit (Cell Technology, Mountain View, CA). This kit uses JC-1, a unique cationic dye, to signal the loss of the MMP. JC-1 accumulates in the mitochondria, which stains red in nonapoptotic cells, while in apoptotic cells, the MMP collapses and thus the JC-1 remains in the cytoplasm as a monomer that stains green under fluorescent light. Briefly, the cells $\left(1 \times 10^{6}\right.$ cells $/ 2 \mathrm{~mL}$ ), induced to undergo apoptosis, were collected by centrifugation at $1,000 \mathrm{rpm}$ for $10 \mathrm{~min}$. Supernatants were removed, $500 \mu \mathrm{l}$ of JC-1 dye was added onto the pellets, and the cells were incubated at $37^{\circ} \mathrm{C}$ in $5 \% \mathrm{CO}_{2}$ for $15 \mathrm{~min}$. Then, they were centrifuged at $1,000 \mathrm{rpm}$ for $5 \mathrm{~min}$, and $2 \mathrm{~mL}$ of assay buffer was added onto the pellets. After centrifugation at $1,000 \mathrm{rpm}$ for $5 \mathrm{~min}$, all pellets were resuspended with $500 \mu \mathrm{l}$ assay buffer and $150 \mu \mathrm{l}$ from each of them was added into the 96-well plate. The aggregate red form has absorption/emission maxima of 585/590 nm, and the monomeric green form has absorption/emission maxima of $510 / 527 \mathrm{~nm}$. The plate was read in these wavelengths by fluorescence ELISA reader (Thermo Varioskan Spectrum, Vantaa, Finland). At the end, green/red (510/585) values were calculated to determine the changes in MMP.

In addition, K562 cells were treated with increasing concentrations of resveratrol in combinations with $\mathrm{C} 8$ :ceramide, PDMP, or SK-1 inhibitor. For this purpose, K562 cells $\left(1 \times 10^{6}\right.$ cells $/ 2 \mathrm{~mL}$ ) were seeded into 6-well plates and then treated with IC50 value of C8:ceramide or IC10 values of PDMP or SK-1 inhibitor. After incubating the plates for $18 \mathrm{~h}$ at $37^{\circ} \mathrm{C}$ in $5 \% \mathrm{CO}_{2}$, increasing concentrations of resveratrol were applied into these plates. After 72-h incubation, the assay procedure mentioned above was executed.

\section{Total RNA Isolation and RT-PCR}

Total RNAs of K562 cells, treated with increasing doses of resveratrol, were extracted using a Ribolock RNA isolation kit (Macherey-Nagel, Düren, Germany) as described by the manufacturer. One $\mu \mathrm{g}$ of each total RNA was reverse transcribed using reverse transcriptase (Moroney Murine Leukemia Virus Reverse Transcriptase, Fermentas, Glenburnie, MD). After 50 min of incubation at $42^{\circ} \mathrm{C}$, the reactions were stopped at $95^{\circ} \mathrm{C}$ for $5 \mathrm{~min}$. The resulting total cDNAs were then used in PCR to measure the mRNA levels of LASS2, LASS4, LASS5, LASS6, SK1, GCS, and $\beta$-actin. The mRNA levels of $\beta$-actin were used as internal positive control. The primer sequences and PCR conditions were as follows: LASS2-F (5'-GCTGGAGATTCAC ATTTTAC- $\left.3^{\prime}\right)$, LASS2-R (5'-GAAGACGATGAAGATGTT GT-3'), LASS4-F (5'-TGCTGTCCAGTTTCAACGAG-3'), LASS4-R (GAGGAAGTGTTTCTCCAGCG-3'), LASS5-F (5' TCCTCAATGGCCTGCTGCTG-3'), LASS5-R (5'-CCCGGC AATGAAACTCACGC-3'), LASS6-F (5'-CTCCCGCACAA TGTCACCTG-3'), LASS6-R (5'-TGGCTTCTCCTGATTG CGTC-3'), SK1-F (5'-CCGACGAGGACTTTGTGCTAAT-3'), SK1-R (5'-GCCTGTCCCCCCAAAGCATAAC-3'), GCS-F (5'-ATGACAGAAAAAGTAGGCT-3'), GCS-R (5'-GGACA CCCCTGAGTGGAA-3'), $\beta$-actin-F (5'-CAGAGCAAGAGA GGCATCCT- $3^{\prime}$ ), and $\beta$-actin-R (5'-TTGAAGGTCTCAAA CATGAT- $3^{\prime}$ ). Two $\mu 1$ of the reverse transcriptase reaction product was amplified using these primers by PCR for 35 cycles, and their levels were normalized to that of $\beta$-actin as described previously (10).

After running the PCR products on agarose gel electrophoresis, quantification of expression levels of the genes were performed by Quantity One-1D-Gel-Imaging program (Biorad, Hercules, CA). The results were normalized to $\beta$-actin levels.

\section{RESULTS}

\section{Resveratrol, C8:ceramide, PDMP, or SK-1 Inhibitor Showed a Dose-Dependent Cytotoxicity on Human K562 Chronic Myeloid Leukemia Cells}

To assess antiproliferative effects of resveratrol, C8:ceramide, PDMP, or SK-1 inhibitor on human K562 cells, the cells were incubated with increasing concentrations of the agents for $72 \mathrm{~h}$ and XTT cell proliferation assay was conducted. The aim of application of C8:ceramide, PDMP, and SK-1 inhibitor is to see whether induction of generation or accumulation of ceramides inhibit proliferation of K562 cells. The results showed that there were dose-dependent decreases in cell proliferation in response to these chemicals as compared to untreated controls. IC50 values of resveratrol (Fig. 1A) and C8:ceramide (Fig. 1B) were calculated from cell proliferation plots and were found to be 80 and $60 \mu \mathrm{M}$, respectively, while IC10 values of PDMP (Fig. 1C) and SK-1 inhibitor (Fig. 1D) were 20 and $7 \mu \mathrm{M}$, respectively. 

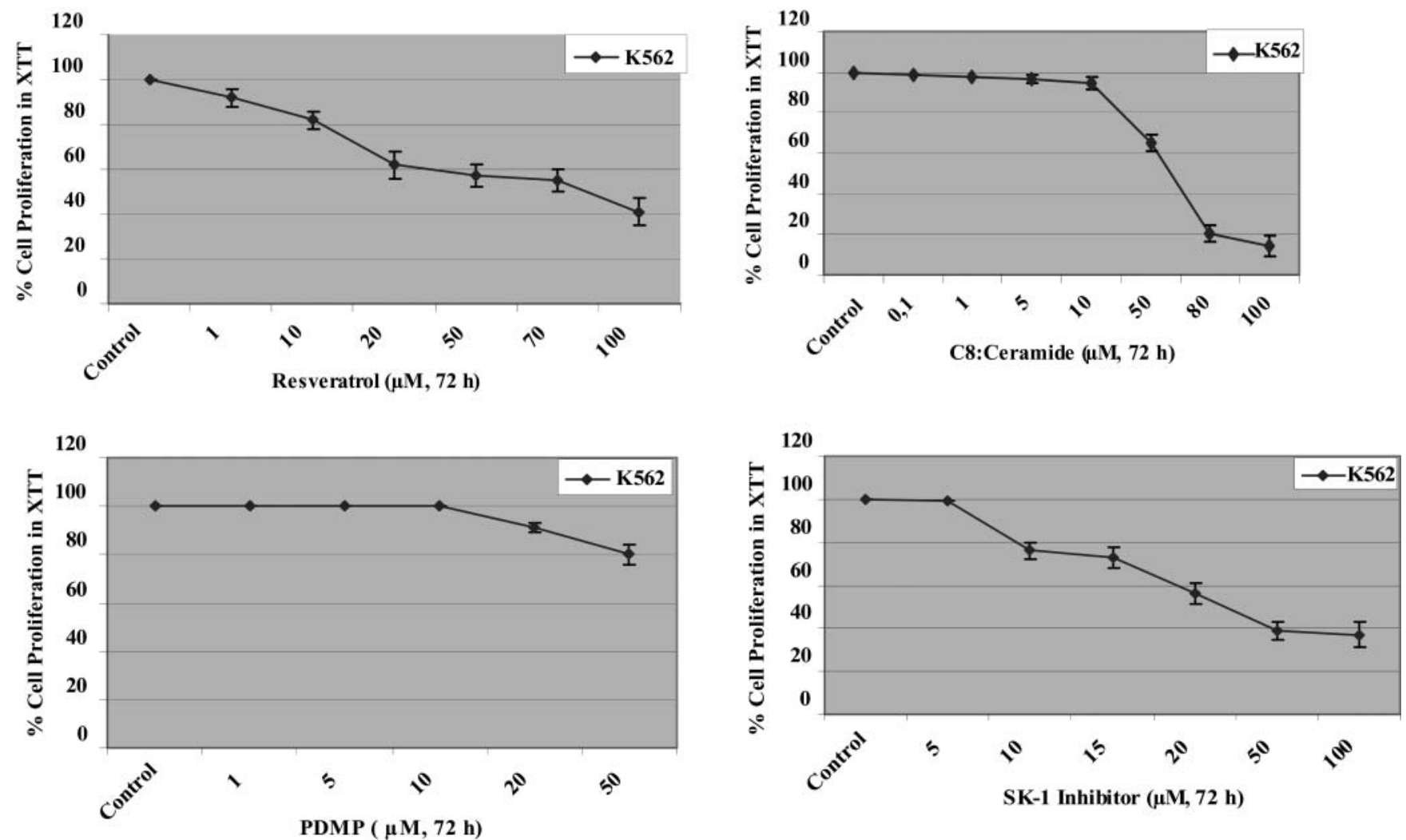

FIG. 1. Cytotoxic effects of resveratrol (A), C8:ceramide (B), PDMP (C), and SK-1 Inhibitor (D) on K562 cells. The IC50 concentration of resveratrol, C8:ceramide, and PDMP and IC10 value of SK-1 inhibitor were calculated from cell proliferation plots. The XTT assays were performed using triplicate samples in at least 3 independent experiments. The error bars represent the standard deviations.

\section{Synergistic Cytotoxic Effects of Combinations of Resveratrol With C8:ceramide, PDMP, or SK-1 Inhibitor on K562 Cells}

In order to examine the possible synergistic cytotoxic effects, the cells were exposed to increasing concentrations of resveratrol from 1 to $100 \mu \mathrm{M}$, together with $60 \mu \mathrm{M}$ C8:ceramide, $20 \mu \mathrm{M}$ PDMP, or $7 \mu \mathrm{M} \mathrm{SK}-1$ inhibitor. The main

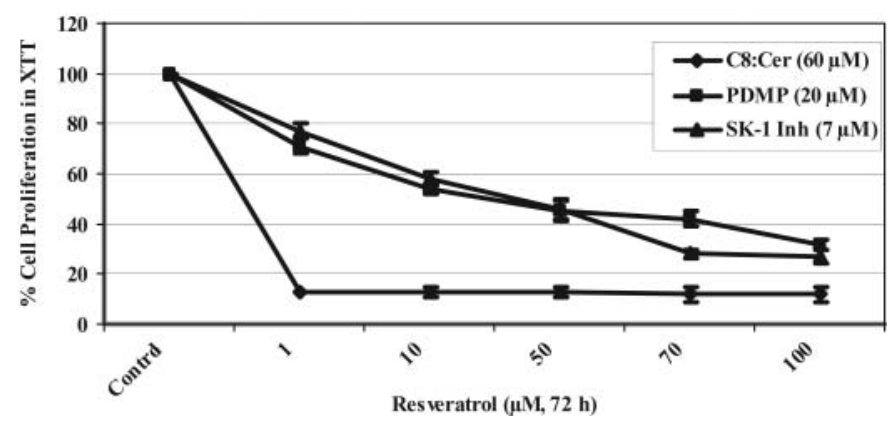

FIG. 2. Synergistic cytotoxic effects coadministration of resveratrol with C8:ceramide or PDMP or SK-1 inhibitor on K562 cells. Cytotoxicity was determined by the XTT cell proliferation assay in a 72-h culture. The XTT assays were performed using triplicate samples in at least 3 independent experiments. The error bars represent the standard deviation. purpose of these combinations was to examine if increasing intracellular concentrations of ceramides increases antiproliferative effects of resveratrol on K562 cells. Combination of 1-, 50-, and $100 \mu \mathrm{M}$ of resveratrol with $60 \mu \mathrm{M} \mathrm{C} 8$ :ceramide decreased proliferation of $\mathrm{K} 562$ cells to $87 \%, 88 \%$, and $89 \%$, respectively, while resveratrol application alone decreased cell proliferation $8 \%, 43 \%$, and $59 \%$, respectively (Fig. 2). The same doses of resveratrol in combination with $20 \mu \mathrm{M}$ PDMP or $7 \mu \mathrm{M}$ SK-1 inhibitor decreased cell proliferation $29 \%, 55 \%$, and $68 \%$, or $23 \%$, $54 \%$, and $73 \%$, respectively (Fig. 2). The data demonstrate that increasing intracellular concentrations of ceramides increased the antiproliferative effects of resveratrol significantly. The most significant effect was observed in combination of C8:ceramide and resveratrol.

\section{Resveratrol Together With C8:ceramide, PDMP, or SK-1 Inhibitor Induces Apoptosis Synergistically in K562 Cells}

In order to see apoptotic effects of resveratrol and increased concentrations of ceramides by ceramide mimetics/inhibitors, we treated cells with different concentrations of resveratrol, C8:ceramide, PDMP, and SK-1 inhibitor alone and examined the changes in caspase- 3 enzyme activity and loss of MMP. In this part of the study, we also investigated if increasing intracellular concentrations of ceramides increases 


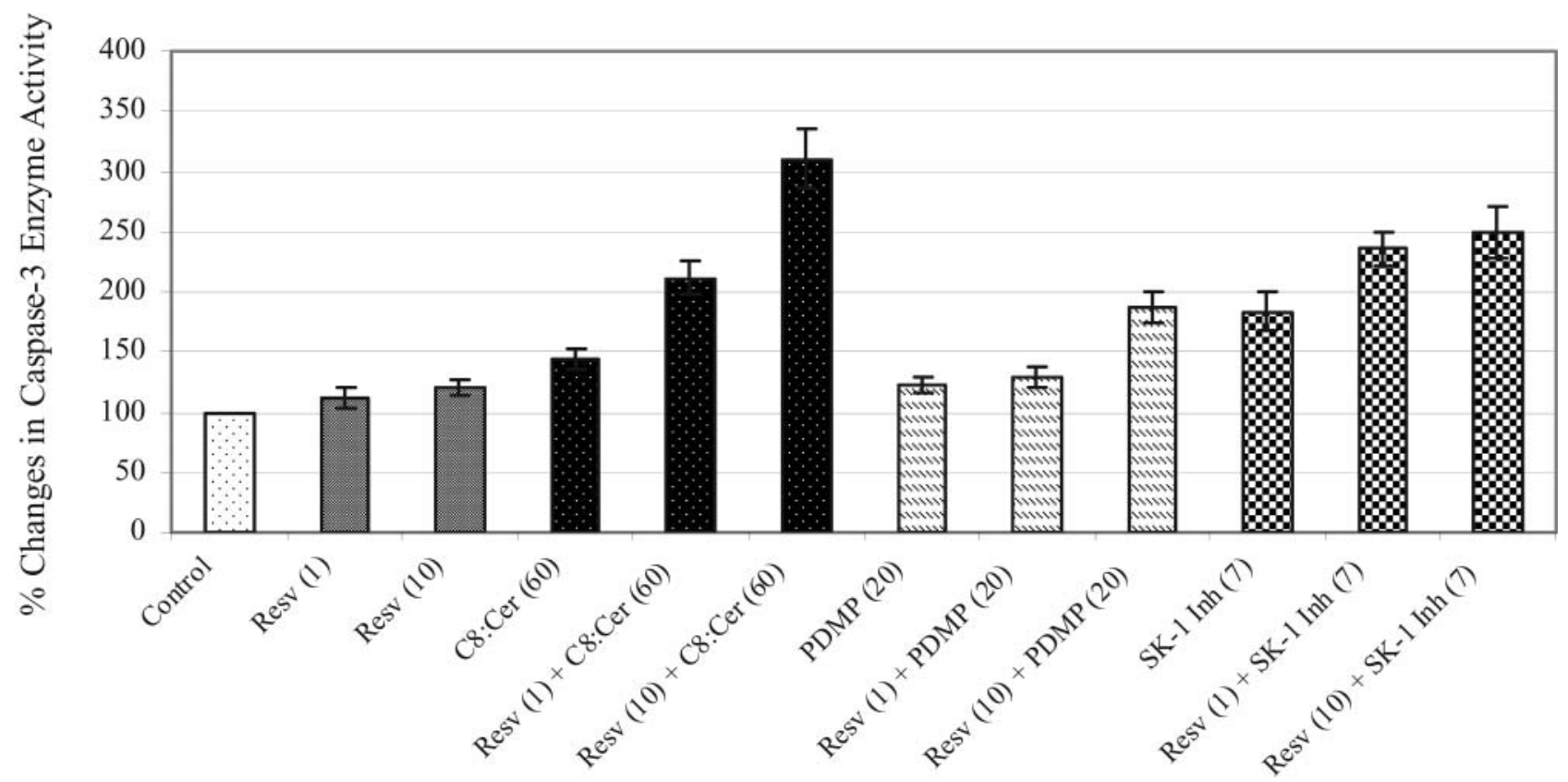

Chemicals $(\mu \mathrm{M}, 72 \mathrm{~h})$

FIG. 3. Changes in caspase- 3 enzyme activity in response to coadministration of resveratrol with C8:ceramide or PDMP or SK-1 inhibitor. The results are the means of 3 independent experiments. The error bars represent the standard deviations, and, when not seen, they are smaller than the thickness of the lines on the graphs.

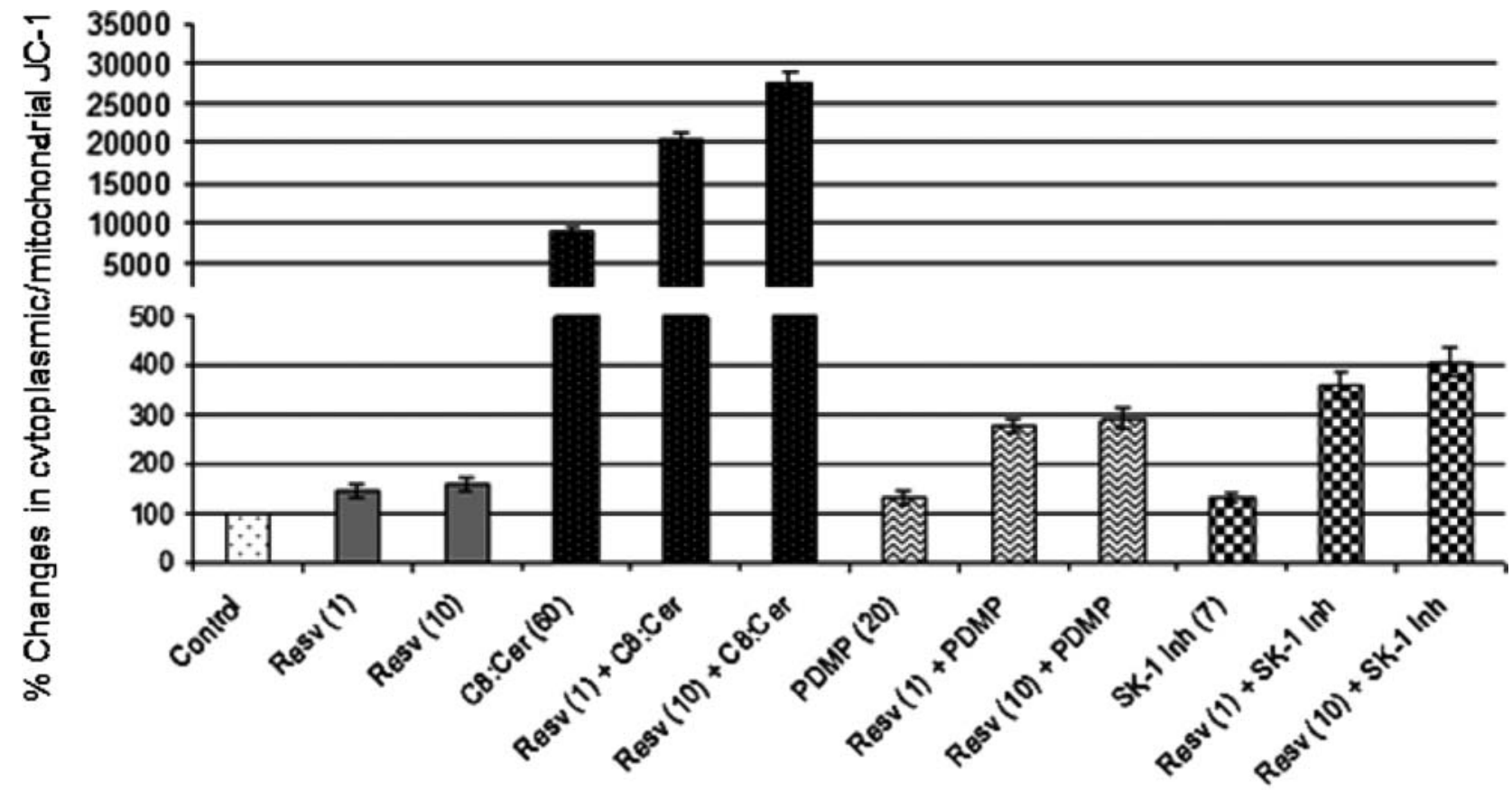

Chemicals $(72 \mathrm{~h}, \mathrm{MM})$

FIG. 4. Changes in cytoplasmic/mitochondrial JC-1 in K562 cells exposed to combinations of resveratrol with C8:ceramide or PDMP or SK-1 inhibitor. The results are the means of 3 independent experiments. The error bars represent the standard deviations, and, when not seen, they are smaller than the thickness of the lines on the graphs. 
apoptotic effects of resveratrol. As shown in Fig. 3, there were 1.12- and 1.21-fold increases in caspase-3 enzyme activity in response to 1 and $10 \mu \mathrm{M}$ resveratrol, respectively. Coadministration of $60 \mu \mathrm{M} \mathrm{C} 8$ :ceramide or $20 \mu \mathrm{M}$ PDMP or 7 $\mu \mathrm{M}$ SK-1 inhibitor with the same doses of resveratrol increased caspase-3 enzyme activity 2.11-, and 3.1- or 1.29-, and 1.87or 2.36- and 2.49-fold, respectively. The same concentrations of C8:ceramide, PDMP and SK-1 inhibitor alone caused 1.44-, $1.22-$, and 1.83 -fold increases in enzyme activity, respectively.

In order to confirm caspase- 3 enzyme activity results and examine the roles of mitochondria in resveratrol-induced apoptosis, we also determined the loss of mitochondrial membrane potential. The results were in agreement with our previous data and have shown that all these chemicals induce apoptosis through induction of loss of MMP. Combination of resveratrol with C8:ceramide, PDMP, or SK-1 inhibitor caused loss of MMP synergistically as compared to any agent alone and any untreated control group (Fig. 4).

\section{Increased LASS Genes Expression and Decreased SK-1 and GCS Genes Expression Induced by Resveratrol in K562 Cells}

In order to determine whether ceramide metabolizing genes are involved in resveratrol-induced apoptosis, K562 cells were treated with increasing concentrations of resveratrol $(1,10,20$, and $50 \mu \mathrm{M}$ ) and expression levels of LASS2, LASS4, LASS5, LASS6, GCS, SK-1, and B-actin were determined by RT-PCR. As shown in Fig. 5 and Table 1, resveratrol inhibited expression levels of GCS and, more significantly, of SK-1 genes. On the contrary, expression levels of LASS2, LASS5, and to a lesser extent LASS4 and LASS6 were increased in response to resveratrol as compared to untreated controls and normalized to B-actin levels (see Fig. 5 and Table 1).

\section{DISCUSSION}

The incidence of cancer is increasing dramatically, and the drugs used in cancer therapy are very expensive and have many side effects. That fact opens the door to investigate novel anticancer agents originated from natural products. Resveratrol has been reported to have cytotoxic effects on various types of cancers (1). On the other hand, resveratrol has been shown to be apoptotic, autophagocytic, a radiotherapy-sensitizer, a cell cycle arrester, an inhibitor of ROS generation in mitochondria, and a regulator of p53 in many cancers $(4,5,7,18-20)$. One of the most important properties of resveratrol is that it has selective toxic effects on cancer cells and far less effect on normal, healthy cells (21). However, the roles of bioactive sphingolipids in resveratrol-induced apoptosis and the effects of resveratrol on ceramide metabolizing genes have never before been examined in cultured chronic myeloid leukemia.

In this study, we examined potential cytotoxic and apoptotic effects of resveratrol and C8:ceramide, an important cellpermeable analogue of natural ceramides (22), which increases

\section{Control $1 \mu \mathrm{M} \quad 10 \mu \mathrm{M} \quad 20 \mu \mathrm{M} \quad 50 \mu \mathrm{M}$}

Lass2

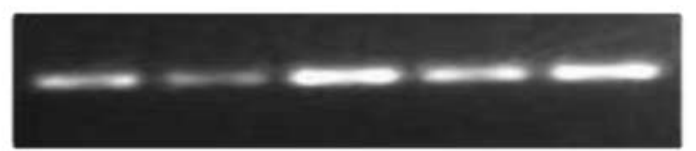

Lass4

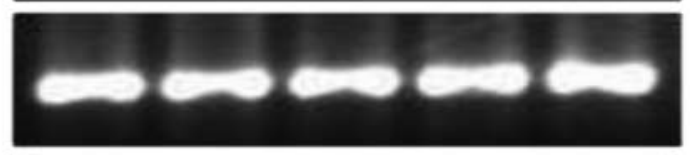

Lass5

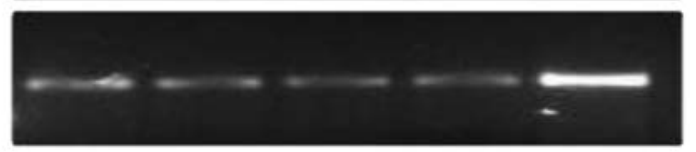

Lass6

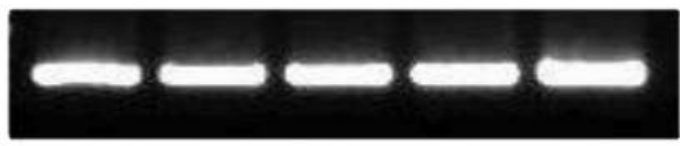

GCS

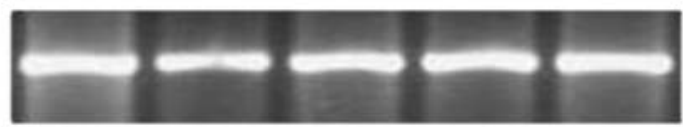

SK-1

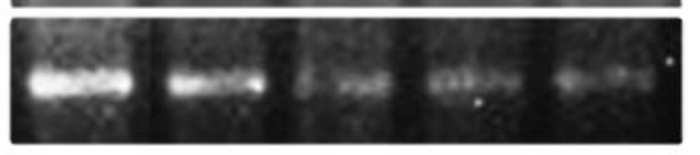

$\beta$-actin

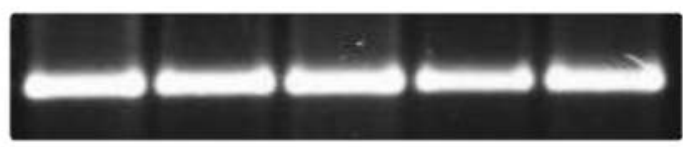

FIG. 5. Expression levels of LASS2, LASS4, LASS5, LASS6, GCS, SK-1, and $\beta$-actin genes in response to resveratrol in K562 cells. One-, 10-, 20-, and $50 \mu \mathrm{M}$ resveratrol were applied to K562 cells for $72 \mathrm{~h}$ and expression levels of ceramide metabolizing genes were determined by RT-PCR. Expression levels of $\beta$-actin was detected as an internal positive control.

intracellular ceramide levels significantly, GCS and SK-1 inhibitors, which increase accumulation of ceramides on K562 cells. We treated K562 cells with increasing concentrations of these chemicals and determined their cytotoxic effects by XTT cell proliferation assay. Our results showed a dose-dependent decrease in cell proliferation in response to resveratrol and in response to increased intracellular concentrations of ceramides. Apoptosis in K562 cells exposed to increasing concentrations of these chemical agents was also evaluated by examining the changes in caspase- 3 enzyme activity and the loss of the mitochondrial membrane potential. The results revealed that resveratrol, C8:ceramide, PDMP, and SK-1 inhibitor might induce apoptosis through increasing caspase- 3 enzyme activity and loss of mitochondrial membrane potential. Increasing intracellular concentrations of ceramides by $\mathrm{C} 8$ :ceramide was suggested to be an effective approach to inhibit cancer cell growth (23). Downregulation of GCS and SK-1 by biochemical and/or molecular techniques are novel effective treatment protocols to regulate cancer cell growth (24-26).

We then assessed combinational treatments of resveratrol with C8:ceramide, the inducer of de novo generation of 
TABLE 1

Quantitative analyses of expression levels of GCS, SK-1, LASS2, LASS4, LASS5, and LASS6 genes in response to resveratrol

\begin{tabular}{lcccccc}
\hline $\begin{array}{l}\text { Resveratrol-Inhibited } \\
\text { Expression Levels }\end{array}$ & GCS & SK-1 & LASS2 & LASS4 & LASS5 & LASS6 \\
\hline Control & 100 & 100 & 100 & 100 & 100 & 100 \\
$1 \mu \mathrm{M}$ Res & 83 & 69 & 91 & 101 & 73 & 105 \\
$10 \mu \mathrm{M}$ Res & 82 & 41 & 174 & 102 & 57 & 109 \\
$20 \mu \mathrm{M}$ Res & 92 & 43 & 182 & 121 & 77 & 129 \\
$50 \mu \mathrm{M}$ Res & 83 & 35 & 191 & 121 & 188 & 131 \\
\hline
\end{tabular}

apoptotic ceramides, PDMP, the inhibitor of GCS, and SK1 inhibitor. When we coadministrate the constant concentrations of C8:ceramide $(60 \mu \mathrm{M})$, PDMP $(20 \mu \mathrm{M})$, or SK-1 inhibitor $(7 \mu \mathrm{M})$ with increasing concentrations of resveratrol (1 to $100 \mu \mathrm{M})$, synergistic antiproliferative effects were observed as compared to any agent alone and untreated controls. Ten $\mu \mathrm{M}$ resveratrol by itself could repress only $18 \%$ of cell proliferation, while the same concentration of resveratrol, together with C8:ceramide, PDMP, or SK-1 inhibitor, inhibited 87\%, $46 \%$, and $42 \%$ of cell proliferation, respectively (Fig. 2). The synergistic apoptotic effects of resveratrol in combination with C8:ceramide, PDMP, or SK-1 inhibitor were also observed by the changes in caspase- 3 enzyme activity and loss of mitochondrial membrane potential. As we increased the intracellular concentrations of ceramides by application of exogenous ceramide or by inhibition of the conversion of ceramides to glucosylceramide or sphingosine-1-phosphate, the sensitivity of K562 cells to resveratrol increased synergistically. Our results were in agreement with the literature since it was clearly shown that both caspases and mitochondrial membrane potential are wellknown downstream targets of ceramides (12).

By our group and some other groups it was reported that resveratrol application results in increases in endogenous ceramide concentrations in prostate, breast (27), and colorectal carcinoma (2) and acute promyelocytic leukemia cells (28). Increases in intracellular concentrations of ceramides were shown by expression levels of the LASS gene family, GCS and SK1 genes, and direct detection of ceramides by LC-MS. There are 6 genes in the LASS gene family that regulate de novo ceramide synthesis (29). Mammalian ceramides exist in various lengths with their different fatty acids, and each member of the LASS gene family is responsible for the generation of these different types of ceramides with different lengths (30). For instance, LASS1 gene is responsible for the synthesis of C18:ceramide (31), whereas LASS2 gene is responsible for the synthesis of C24:ceramide (32), and LASS4 gene is responsible for the synthesis of C22:ceramide (33). However, LASS5 and LASS6 genes are responsible for the synthesis of C14:ceramide and C16:ceramide $(34,35)$. RT-PCR results of this study have shown for the first time that resveratrol treatment resulted in the upregulation of LASS2, LASS4, LASS5, and LASS6 genes in a dose-dependent fashion in human K562 CML cells. There were significant decreases in the expression levels of GCS and SK-1 genes in response to increasing concentrations of resveratrol in K562 cells. These results suggest that resveratrol increases intracellular concentrations of ceramides via induction of its de novo synthesis and also inhibition of the conversion of endogenous apoptotic ceramide to antiapoptotic glucosylceramide and sphingosine-1-phosphate molecules.

In conclusion, we confirmed the cytotoxic effects of resveratrol on K562 cells and showed that there were synergistic apoptotic effects of the combinations of resveratrol with C8:ceramide or PDMP or SK-1 inhibitor on K562 CML cells. More importantly, we have shown for the first time that resveratrol triggers apoptosis through increasing expression levels of LASS genes and inhibiting the expression levels of GCS and SK-1 in human K562 CML cell lines. Taken together, all these results may open the way toward using resveratrol and ceramides as a novel therapeutic or supportive approach for the management of CML.

\section{ACKNOWLEDGMENTS}

We thank the Biotechnology and Bioengineering Center staff of Izmir Institute of Technology for their help and technical support. This study was supported by the Turkish Society of Hematology and by the Turkish Academy of Sciences, Outstanding Young Investigator Programme, to Y. B.

\section{REFERENCES}

1. Sahin F, Avci ÇB, Avcu F, Ural AU, Sarper M, et al.: Red grapeseed extract and its compound resveratrol exert cytotoxic effect to various human cancer lines. Turk J Hematol 24, 102-109, 2007.

2. Ulrich S, Huwiler A, Loitsch S, Schmidt H, and Stein JM: De novo ceramide biosynthesis is associated with resveratrol-induced inhibition of ornithine decarboxylase activity. Biochem Pharmacol 74, 281-289, 2007.

3. Park JS, Kim KM, Kim MH, Chang HJ, Baek MK, et al.: Resveratrol inhibits tumor cell adhesion to endothelial cells by blocking ICAM-1 expression. Anticancer Res 29, 355-362, 2009.

4. Scarlatti F, Sala G, Ricci C, Maioli C, Milani F, et al.: Resveratrol sensitization of DU145 prostate cancer cells to ionizing radiation is associated to ceramide increase. Cancer Lett 253, 124-130, 2007.

5. Liao HF, Kuo CD, Yang YC, Lin CP, Tai HC, et al.: Resveratrol enhances radiosensitivity of human non-small-cell lung cancer NCI-H838 cells accompanied by inhibition of nuclear factor-kappa B activation. J Radiat Res 46, 387-393, 2005. 
6. Gatz SA and Wiesmüller L: Take a break-resveratrol in action on DNA. Carcinogenesis 29, 321-332, 2008.

7. Bhardwaj A, Sethi G, Vadhan-Raj S, Bueso-Ramos C, Takada Y, et al.: Resveratrol inhibits proliferation, induces apoptosis, and overcomes chemoresistance through down-regulation of STAT3 and nuclear factorkappaB-regulated antiapoptotic and cell survival gene products in human multiple myeloma cells. Blood 109, 2293-2302, 2007.

8. Koca E and Haznedaroglu IC: Imatinib mesylate and the management of chronic myeloid leukemia (CML). Turk J Haematol 22, 161-172, 2005.

9. Cardama AQ and Cortes J: Molecular biology of bcr-abl1-positive chronic myeloid leukemia. Blood 113, 1619-1630, 2009.

10. Baran Y, Salas A, Senkal C. E, Gunduz U, Bielawski J, et al.: Alterations of ceramide/sphingosine 1-phosphate rheostat involved in the regulation of resistance to imatinib-induced apoptosis in K562 human chronic myeloid leukemia cells. J Biol Chem 282, 10922-10934, 2007.

11. Senchenkov A, Litvak DA, and Cabot MC: Targeting ceramide metabolism - a strategy for overcoming drug resistance. J Natl Cancer Inst 93, 347-357, 2001.

12. Ogretmen B and Hannun YA: Bioactive sphingolipids in cancer pathogenesis and treatment. Nat Rev 4, 604-616, 2004.

13. Itoh M, Kitano T, Watanabe M, Kondo T, Yabu T, et al.: Possible role of ceramide as an indicator of chemoresistance: decrease of the ceramide content via activation of glucosylceramide synthase and sphingomyelin synthase in chemoresistant leukemia. Clin Cancer Res 8, 415-423, 2003.

14. Pettus BJ, Chalfant CE, and Hannun YA: Ceramide in apoptosis: an overview and current perspectives. Biochimica et Biophysica Acta 1585, 114-125, 2002.

15. Dolfini E, Roncoroni L, Dogliotti E, Sala G, Erba E et al.: Resveratrol impairs the formation of MDA-MB-231 multicellular tumor spheroids concomitant with ceramide accumulation. Cancer Lett 249, 143-147, 2007.

16. Signorelli P, Munoz-Olaya JM, Gagliostro V, Casas J, Ghidoni R, et al.: Dihydroceramide intracellular increase in response to resveratrol treatment mediates autophagy in gastric cancer cells. Cancer Lett 282, 238-243, 2009.

17. Nica AF, Tsao CC, Watt JC, Jiffar T, Kurinna S, et al.: Ceramide promotes apoptosis in chronic myelogenous leukemia-derived $\mathrm{K} 562$ cells by a mechanism involving caspase-8 and JNK. Cell Cycle 7, 3362-3370, 2008.

18. Dong Z: Molecular mechanism of the chemopreventive effect of resveratrol. Mut Res 523-524, 145-150, 2003.

19. Fulda $S$ and Debatin KM: Resveratrol modulation of signal transduction in apoptosis and cell survival: a mini-review. Cancer Det Prev 30, 217-223, 2006.

20. Shin SM, Cho IJ, and Kim SG: Resveratrol protects mitochondria against oxidative stress through AMP-activated protein kinase-mediated glycogen synthase kinase-3beta inhibition downstream of poly(ADPribose)polymerase-LKB1 pathway. Mol Pharmacol 76, 884-895, 2009.

21. Tsan MF, White JE, Maheshwari JG, and Chikkappa G: Anti-leukemia effect of resveratrol. Leuk Lymphoma 43, 983-987, 2002.
22. Tokudomea Y, Saitoa Y, Satoa F, Kikuchia M, Hinokitania T, et al.: Preparation and characterization of ceramide-based liposomes with high fusion activity and high membrane fluidity. Colloids and Surfaces B: Biointerfaces 73, 92-96, 2009.

23. Saddoughi SA, Song P, and Ogretmen B: Roles of bioactive sphingolipids in cancer biology and therapeutics. Subcell Biochem 49, 413-440, 2008.

24. Gouaze-Andersson V, Yu JY, Kreitenberg AJ, Bielawska A, Giuliano AE, et al.: Ceramide and glucosylceramide upregulate expression of the multidrug resistance gene MDR1 in cancer cells. Biochimica Biophysica Acta 1771, 1407-1417, 2007.

25. Gouaze V, Liu YY, Prickett CS, Yu JY, Giuliano AE, et al.: Glucosylceramide synthase blockade down-regulates P-glycoprotein and resensitizes multidrug-resistant breast cancer cells to anticancer drugs. Cancer Res $\mathbf{6 5}$, 3861-3867, 2005

26. French KJ, Upson JJ, Keller SN, Zhuang Y, Yun JK, et al.: Antitumor activity of sphingosine kinase inhibitors. J Pharmacol Exp Ther 318, 596-603, 2006.

27. Minutolo F, Sala G, Bagnacani A, Bertini S, Carboni I, et al.: Synthesis of a resveratrol analogue with high ceramide-mediated proapoptotic activity on human breast cancer cells. J Med Chem 48, 6783-6786, 2005.

28. Cakir Z, Saydam G, Sahin F, and Baran Y: The roles of bioactive sphingolipids in resveratrol-induced apoptosis in HL60 acute myeloid leukemia cells. J Cancer Res Clin Oncol [Epub ahead of print], 2010.

29. Obeid LM and Hannun YA: Ceramide, stress, and a "LAG" in aging. Sci Aging Knowledge Environ 39, PE27, 2003.

30. Pewzner-Jung Y, Ben-Dor S, and Futerman AH: When do Lasses (longevity assurance genes) become CerS (ceramide synthases)? Insights into the regulation of ceramide synthesis. J Biol Chem 281, 25001-25005, 2006.

31. Venkataraman K, Riebeling C, Bodennec J, Riezman H, Allegood JC, et al.: Upstream of growth and differentiation factor 1 (uog1), a mammalian homolog of the yeast longevity assurance gene 1 (LAG1), regulates $\mathrm{N}$-stearoyl-sphinganine (C18-(dihydro)ceramide) synthesis in a fumonisin B1-independent manner in mammalian cells. J Biol Chem 277, 35642-35649, 2002.

32. Mizutani Y, Kihara A, and Igarashi Y: Mammalian Lass6 and its related family members regulate synthesis of specific ceramides. Biochem $J \mathbf{3 9 0}$, 263-271, 2005.

33. Riebeling C, Allegood JC, Wang E, Merrill AH, Futerman AH: Two mammalian longevity assurance gene (LAG1) family members, trh 1 and trh4, regulate dihydroceramide synthesis using different fatty acyl-CoA donors. J Biol Chem 278, 43452-43459, 2003.

34. Weinmann A, Galle PR, and Teufel A: LASS6, an additional member of the longevity assurance gene family. Int J Mol Med 16, 905-910, 2005.

35. Xu Z, Zhou J, McCoy DM, and Mallampalli RK: LASS5 is the predominant ceramide synthase isoform involved in de novo sphingolipid synthesis in lung epithelia. J Lipid Res 46, 1229-1238, 2005. 
Copyright of Nutrition \& Cancer is the property of Taylor \& Francis Ltd and its content may not be copied or emailed to multiple sites or posted to a listserv without the copyright holder's express written permission.

However, users may print, download, or email articles for individual use. 